\title{
Acesso à experiência em primeira pessoa na pesquisa em Saúde Mental
}

\author{
Access to first-person experience in research into mental health
}

Erotildes Maria Leal ${ }^{1}$

Octavio Domont de Serpa Junior ${ }^{2}$

${ }^{1}$ Faculdade de Medicina, Universidade Federal do Rio de Janeiro. Rua Aloísio Gomes 50, Granja dos Cavaleiros. Polo Cidade Universitária. 27.930-560 Macaé RJ.

erotildesleal@macae.ufrj.br ${ }^{2}$ Programa de Psiquiatria, Instituto de Psiquiatria, Universidade Federal do Rio de Janeiro.

\begin{abstract}
This article presents and discusses the epistemological and methodological challenges related to the empirical study of first-person experience in mental health research. Considering the field of qualitative research, the methodological principles of phenomenology and medical anthropology are examined from a historical and conceptual perspective. The main operational concepts of the phenomenological method applied to empirical research, as well as their two main lines of approach, namely descriptive and psychological/transcendental phenomenology and hermeneutical or interpretative phenomenology, are described. The contributions of medical anthropology are studied especially with respect to the experience of illness and its forms of narrative. Lastly, considering the distinction between experience and narrative based on the theoretical benchmarks of phenomenology and medical anthropology, a more in-depth debate on access to first-person experience is conducted.
\end{abstract}

Key words Experience, Narrative, Methodology, Phenomenology, Medical anthropology
Resumo Este artigo apresenta e discute os desafios epistemológicos e metodológicos relacionados ao estudo empírico da experiência em primeira pessoa na pesquisa em Saúde Mental. Considerando-se o campo da pesquisa qualitativa em saúde examinam-se os princípios metodológicos da fenomenologia e da antropologia médica em uma perspectiva histórica e conceitual. São apresentados os principais conceitos operatórios do método fenomenológico aplicado à pesquisa empírica, bem como suas duas principais abordagens, a fenomenologia descritiva e psicológica/transcendental e a fenomenologia hermenêutica ou interpretativa. As contribuições da Antropologia Médica são trabalhadas sobretudo no que concerne à experiência de adoecimento e suas modalidades narrativas. Por fim, considerando-se a distinção entre experiência e narrativa, a partir dos referenciais teóricos da Fenomenologia e da Antropologia Médica, aprofunda-se o debate sobre o acesso à experiência em primeira pessoa.

Palavras-chave Experiência, Narrativa, Metodologia, Fenomenologia, Antropologia médica 


\section{Introdução}

O surgimento, na década de 80 , da Medicina Baseada em Evidências (MBE) alçou a uma posição de hegemonia os estudos sobre os processos saúde/doença com desenhos experimentais baseados em métodos quantitativos ${ }^{1}$. Isto não significou, entretanto, o abandono das pesquisas qualitativas em saúde. No caso específico da saúde/doença mental, os estes têm crescido significativamente nas últimas décadas, no Brasil e no mundo.

A partir do final da década seguinte reconheceu-se que a observação empírica dos processos de saúde/doença das populações - feita sobretudo por meio de estudos com desenho experimental e observacional, privilegiados pela MBE - produziu conhecimento limitado para o julgamento de um caso clínico particular. Para a tomada de decisão diante dos pacientes reais, achados dos campos da epidemiologia e das ciências básicas precisam estar articulados a outros que emergem de histórias contextualizadas, produzidos pelas metodologias qualitativas de pesquisa ${ }^{2}$. Elementos relacionados aos contextos sociais e humanos e às experiências vividas pelas pessoas em seus processos de adoecimento ${ }^{3}$ constituem essas outras evidências.

Viu-se crescerem então estudos sobre vivências, valores, concepções e práticas que os sujeitos têm sobre eventos relacionados à saúde e doença. Dentre estes, entretanto, preponderam análises sociantropológicas sobre a dimensão da ação humana que decorre da introjeção das normas previamente estabelecidas no âmbito social. Tais análises, embora se ocupem da introjeção de elementos culturais ou simbólicos ou dos conflitos existentes nestes processos interativos ${ }^{4}$, têm escopo limitado para discutir a ação humana em sua complexidade. A experiência de vida cotidiana não se define exclusivamente a partir das representações introjetadas do mundo nem como produto meramente individual.

Os estudos sobre experiência do adoecimento de Kleinman ${ }^{5}$, Kleinman et al. ${ }^{6}$ e Young ${ }^{7}$, nas décadas de 70 e 80 , destacam a necessidade de se tomar como objeto de investigação a situação de adoecimento vivida em contextos culturais concretos. Eles tematizam a dimensão criativa dos indivíduos adoecidos no manejo com o seu sofrimento, indicam que a ação humana não é necessariamente submetida a uma lógica sistêmica e que a análise das representações sociais é insuficiente, porque exclui a experiência e as relações que o sujeito adoecido constrói com ele mesmo e com os outros. Todavia, a prioridade dada às representações sociais, em detrimento do vivido, permanece quando tais estudos tentam explicar as crenças que os indivíduos têm sobre saúde e doença. Neste contexto, ganharam relevância os estudos de base fenomenológica que buscam atribuir outro sentido à noção de experiência do adoecimento.

O termo "experiência", na tradição fenomenológica, dirá do modo de ser do sujeito no mundo. Indicará como estamos mergulhados no mundo e nele agimos no tempo e no espaço, e que isto está para além do modo como o representamos cognitivamente. Os sentidos possíveis do vivido são dados pela dimensão encarnada da existência. O corpo, fundamento da nossa inserção no mundo, é tomado como aquilo que liga natureza e cultura, indicando a anterioridade da ação sobre a reflexão.

Nos estudos sobre experiência do adoecimento na perspectiva fenomenológica interessa conhecer como a interação com o mundo é vivenciada pelo adoecido. Concebe-se que a relação que a pessoa constituirá com o mundo, mediada por tal experiência, também é constituinte da "realidade" vivida, ou pelo menos de parte dela. Narrativas generalizantes sobre a interação com o mundo, entretanto, presentes em relatos que informam, de modo abstrato, sobre esta interação ou que a explicam, mesmo que provocadas pelo adoecimento, não são capazes de revelar essa dimensão da experiência que não é completamente prédeterminada porque está articulada a contextos interativos particulares. Como acessar esses aspectos individuais, específicos, idiográficos, da experiência vivida dos adoecidos? Se as narrativas são o modo privilegiado para acessar o que o outro vivencia em sua experiência de adoecimento, como trata-las para garantir que não se restrinjam à dimensão das representações abstratas das doenças e das suas consequências gerais sobre a vida cotidiana? Que desafios metodológicos se impõem para a realização dessa tarefa?

Três seções são desenvolvidas neste artigo com a finalidade de enfrentar estas perguntas. Na primeira, apresenta-se breve panorama dos métodos fenomenológicos aplicados à pesquisa empírica da experiência vivida no campo da saúde. Na segunda, visita-se a noção da experiência do adoecimento à luz da antropologia médica e seus métodos de estudo. Na última seção, retoma-se a discussão dos desafios metodológicos de produção desse tipo de narrativa a partir do exame das noções de experiência e narrativa. 


\section{Os métodos fenomenológicos e o estudo de experiência}

A Fenomenologia, corrente filosófica inaugurada com a obra de Edmund Husserl (1859-1938) no início do século XX, em atmosfera intelectual de crise do pensamento filosófico e do racionalismo científico, aspirava à formulação de um método rigoroso de investigação para as pesquisas filosóficas e psicológicas sobre a experiência humana ${ }^{8}$. Grosso modo, é possível afirmar que o objeto da fenomenologia é o estudo da experiência, com foco na relação intencional onde consciência e mundo constituem-se mutuamente e coexistem como polos inseparáveis. Em sua ambição originária, todavia, a Fenomenologia filosófica não se pretendia uma Psicologia Descritiva, mesmo que o caminho inicial de Husserl tenha percorrido esta paisagem. Para Husserl, o método fenomenológico servia ao propósito de investigação do sujeito transcendental, não instanciado em nenhuma individualidade empírica.

No campo da filosofia, a diversidade de abordagens descritas como Fenomenologia, frequentemente identificada a partir dos filósofos que contribuíram para seu desenvolvimento, é percebida também no interior da obra de seus principais autores. Zahavi ${ }^{9}$ exemplifica isso quando diz que a obra de Husserl pode ser dividida em dois tempos distintos - uma fenomenologia do início, onde a teoria da intencionalidade é central, e uma tardia, na qual as noções de corpo, intersubjetividade e tempo produzem uma virada filosófica - sendo aberta a possibilidades de identificação de novas perspectivas, dependendo dos caminhos que se privilegie em sua leitura e interpretação.

O reconhecimento da existência de abordagens dinâmicas, abertas e em desenvolvimento exigiu a adjetivação da Fenomenologia para descrevê-la e explicitar o referencial teórico privilegiado, como a Fenomenologia Transcendental identificada com Husserl e intérpretes como Fink -, Fenomenologia Existencial - associada principalmente com Heidegger, Sartre e Merleau-Ponty - e Fenomenologia Hermenêutica - associada a Heidegger, Gadamer e Ricoeur. No âmbito da sua aplicação na pesquisa empírica, o movimento não foi diferente, e o uso do método fenomenológico no cenário das metodologias qualitativas também não se dá de uma única forma.

Foi a partir das décadas de 60 e 70 do século passado que discussões sobre sua aplicabilidade no campo da pesquisa empírica ganharam visibilidade. O desafio de transpor um conhecimen- to da filosofia para o campo da pesquisa empírica é grande, principalmente por ser a fenomenologia, enquanto pensamento filosófico, uma tradição viva, em movimento, comportando perspectivas diferentes ${ }^{10}$. No campo específico do adoecimento mental a utilização do método fenomenológico na investigação dos estados mentais, protagonizada por Karl Jaspers, Ludwing Binswanger, Wolfgang Blankenburg, dentre outros, foi anterior a este período. Estes autores, todavia, utilizaram esse instrumental para o estudo de casos clínicos. Agora o desafio era outro.

A transposição, para o campo da investigação empírica, de um método filosófico que se dispunha a contribuir para o desenvolvimento de uma filosofia "tão rigorosa quanto a ciência"11 é tarefa tão prenhe de obstáculos que, autores como Giorgi ${ }^{12}$, que fizeram uso do método fenomenológico na pesquisa empírica em psicologia, afirmam que, nesta seara, encontrar "desviantes” da fenomenologia é mais fácil do que achar "seguidores".

Apesar da variação, alguns conceitos operatórios fundamentais da Fenomenologia filosófica-intencionalidade, redução fenomenológica e redução transcendental - são incorporados ao método fenomenológico de pesquisa empírica e constituem sua marca distintiva no universo da pesquisa qualitativa.

O conceito de intencionalidade caracteriza a estrutura básica da experiência: toda consciência é sempre consciência de alguma coisa e todo objeto o é para uma consciência. Sujeito e mundo estão necessariamente intrincados; a experiência corporificada abre perspectiva para uma relação de significação com o entorno.

O objeto do método fenomenológico na pesquisa empírica é o vivido subjetivo, a experiência corporal que o acompanha, o ponto de vista singular de quem vive a experiência e sobre o qual se apóia posteriormente a reflexão, buscando explicitar o que está implícito na experiência. Assim, deixa-se de buscar narrativas abstratas ou generalizantes ancoradas em representações coletivas e no conhecimento comum, afastadas do caráter singular das experiências relacionadas ao fenômeno estudado.

O estudo da experiência subjetiva deve começar com a redução fenomenológica ou époché. Esta consiste na "colocação entre parênteses" do conjunto de crenças que sustentam as certezas cotidianas do que se considera a realidade objetiva (material ou mental) que subsiste independente de qualquer perspectiva. Este movimento de suspensão das crenças abre caminho para o desvelamen- 
to da perspectiva própria aos participantes da pesquisa acerca do fenômeno estudado e dos significados das suas experiências singulares.

A impossibilidade de uma époché completa já foi indicada por Merleau-Ponty ${ }^{13}$ no escopo da Fenomenologia Filosófica. "O maior ensinamento da redução [fenomenológica] é a impossibilidade de uma redução completa [...] porque nós estamos no mundo, mesmo nossas reflexões têm lugar no fluxo temporal que elas procuram captar". Quando se trata da transposição do método fenomenológico para a pesquisa empírica de orientação fenomenológica, as limitações da époché são ainda mais evidentes, pois o acesso à experiência vivida dos sujeitos de pesquisa é sempre mediado pelas referências teóricas do pesquisador, que orientam a própria formulação da questão da pesquisa. A époché não é o abandono ou a eliminação das nossas crenças, mas sua suspensão, temporária e incompleta, provocando no pesquisador um movimento reflexivo que cultiva de forma persistente a indagação ${ }^{14}$.

A redução transcendental é operada a fim de estudar como se constitui a experiência, deslocando o foco do objeto da experiência para a experiência ela mesma. Se habitualmente o foco é dirigido ao conteúdo dos diferentes estados mentais, - pensamento, memória, percepção - na redução transcendental passa-se destes conteúdos para o estudo das condições de possibilidade dos próprios estados mentais - pensar, lembrar, perceber. A constituição da experiência é estudada tanto em relação às suas condições de possibilidade atuais e individuais - trajetória biográfica e condições de corporificação do sujeito - quanto em referência aos horizontes de sentido - universo simbólico no qual o sujeito se insere ${ }^{15}$.

Os esforços para aplicar o método fenomenológico à prática científica podem ser apresentados em duas grandes vertentes: a fenomenologia empírica que, grosso modo, a partir de descrições compreensivas da experiência, busca estabelecer sua estrutura essencial, e a fenomenologia experimental, que integra protocolos experimentais de pesquisa a descrições e relatos de experiências vividas ${ }^{16}$. Nesta seção, duas variações da primeira vertente, que alcançaram grande visibilidade no campo das investigações psicológicas e em saúde, serão apresentadas.

No campo das pesquisas qualitativas em psicologia e saúde, na perspectiva da fenomenologia empírica, pelo menos dois grandes modos de abordagem podem ser indicados: a) o primeiro, mais fiel ao método husserliano, exemplificado tanto pela tradição mais estritamente descritiva ${ }^{12,17}$ como pela fenomenologia psicológica/transcendental $^{18}$, tem o foco na descrição textural (de textura) - "o quê" - e estrutural - "como" - da experiência e menos na interpretação; b) o segundo, bem representado pela fenomenologia hermenêutica ou análise fenomenológica interpretativa ${ }^{19,20}$, mescla a perspectiva husserliana com a abordagem hermenêutica de Heidegger e Gadamer e está orientado para a descrição da experiência vivida e a interpretação do seu significado.

A tradição descritiva teve na Universidade de Duquesne, na década de 60 e 70, seu centro de desenvolvimento. Dentre aqueles que deram consequência ao trabalho iniciado por Adrian van Kaam, na década de 50, Amedeo Giorgi tem sido citado como seu principal representante. $\mathrm{O}$ eixo desta perspectiva metodológica é uma análise descritiva e compreensiva da experiência, produzida pela busca, nas narrativas estudadas, de elementos temáticos essenciais constitutivos do sentido da experiência em questão. Quatro passos essenciais são propostos. Com o primeiro obtém-se o sentido do todo descrito, ou seja, de todo o texto transcrito. Em seguida discriminamse as unidades de significado. Depois disso transforma-se a linguagem comum das unidades de significado numa linguagem científica. Por último, apresenta-se a síntese das unidades de significado transformadas numa estrutura descritiva do significado da experiência. As unidades de significado, constituidas pela atitude ativa do investigador, indicam um significado que é relevante para a experiência estudada e como tal constituinte do todo. A transformação da unidade de significado - da linguagem do participante para a linguagem científica - se dá por um processo reflexivo da variação imaginativa, de acordo com a disciplina que orienta o estudo, em acordo com a perspectiva fenomenológica. Vale finalmente ressaltar que a síntese, estrutura que expressa como o fenômeno estudado faz sentido, é meio e não fim, e não necessariamente terá que ser única. Deste modo as estruturas não são universais, mas revelam, em relação ao contexto do fenômeno em análise, aquilo que é geral ou típico.

A tradição psicológica ou transcendental ${ }^{18}$ opera de forma semelhante, identificando a experiência vivida no material empírico coletado a fim de descrever como os participantes vivenciam os fenômenos estudados. São identificadas declarações significativas que embasam agrupamentos de sentido, produzindo a descrição textural. Esta é submetida à variação imaginativa para produzir a descrição estrutural, que apresenta como os participantes experienciaram o fe- 
nômeno em foco em termos das estruturas de tempo, espaço, corpo e intersubjetivas. Da síntese das duas modalidades descritivas, textural e estrutural, resulta a estrutura invariante ou essencial do fenômeno estudado. Como o conhecimento gerado na pesquisa fenomenológica é sempre resultado de uma perspectiva de exame, a estrutura invariante ou essência pode ser sempre modificada ou completada por novas pesquisas que explorem outras perspectivas de análise sobre o mesmo fenômeno, não sendo, portanto, equivalente a uma essência platônica ${ }^{21}$.

A Análise Fenomenológica Interpretativa ${ }^{19}$ acrescenta esforço interpretativo aos conceitos operatórios descritos acima. O objetivo é explorar em detalhes a experiência vivida dos participantes, e os modos como lhes dão sentido. O trabalho de interpretação funciona segundo uma dupla hermenêutica: como o participante dá sentido para a sua experiência e como o pesquisador dá sentido para o trabalho de significação do participante. O pesquisador trabalha, então, com dois objetivos: descrever como deve ser e compreender o mundo dos participantes; e desenvolver uma análise mais abertamente interpretativa, que coloca a descrição em relação a um contexto teórico, cultural e social mais amplo, fornecendo comentário crítico e conceitual para o esforço do participante de dar sentido a sua experiência.

Ambas as abordagens - a mais fiel ao método husserliano, exemplificada acima pelas tradições descritiva e fenomenológica psicológica/transcendental, e aquela que mescla a perspectiva husserliana com a abordagem hermenêutica de Heidegger e Gadamer, exemplificada pela tradição fenomenológica interpretativa - são fundamentalmente idiográficas, enfatizam o particular, a experiência subjetiva "singularmente corporificada, situada, perspectivada"19. É importante salientar que o acesso à experiência singular, em ambos os caminhos metodológicos, é sempre parcial e complexo, construído pelo participante e pelo pesquisador em interação e contexto.

\section{A tradição e os métodos antropológicos de estudo da experiência do adoecimento}

Os estudos sobre a experiência do adoecimento ganham destaque a partir das décadas de 70/80, com a Antropologia Médica. A diferenciação dos termos disease, sickness e illness, indicada por Kleinman et al. ${ }^{6}$, frequentemente traduzidos de modo indistinto para o português como "doença", impulsionou e redefiniu fronteiras previamente existentes, dando nova moldura a estes estudos. Disease, utilizado para indicar as alterações relacionadas com a estrutura funcional do corpo, descreve o fenômeno do adoecimento visto a partir da perspectiva de um observador externo, que toma a doença como objeto de conhecimento e intervenção. Sickness indica o processo que atribui valor social, econômico, político a fenômenos identificados como doença e problemas de saúde ${ }^{22,23}$ e os torna socialmente significativos. Illness engloba a perspectiva subjetiva/ intersubjetiva de quem vivencia o sofrimento e o modo como a pessoa doente, membros de sua família e mesmo pessoas que compõem uma rede social mais ampla vivenciam, percebem, nomeiam, significam, explicam, interpretam, negociam e compartilham alianças e sentidos ${ }^{22,24}$, indicando a situação vivida, corporificada e situada em contextos culturais concretos. Traduzida aqui como experiência de adoecimento, a categoria illness descreve a dimensão do processo de adoecimento que articula a autopercepção de mudanças na sensação corporal à rotulação de "doente" pela pessoa em sofrimento, família ou membros da comunidade mais ampla. Histórias de vida, significados e ações dos sujeitos em busca da cura, do tratamento, do restabelecimento e da normalização das condições de existência perturbadas pela doença constituem-se aspectos integrantes da própria experiência do adoecer.

Os estudos sobre a experiência de adoecimento buscam, a partir desta reconfiguração, conhecer como o sujeito vivencia e narra uma determinada situação de adoecimento. $\mathrm{O}$ que se passa no meu corpo/mente? O quê e por que aconteceu? Por que aconteceu comigo? Por que agora? O que fazer e a quem pedir ajuda? Estas são algumas das indagações que, dirão Kleinman e Benson ${ }^{25}$, quem vivencia qualquer experiência de adoecimento atravessa em algum momento, de modo particular.

Essa inflexão produzida por Kleinman no campo dos estudos socioantropológicos sobre o adoecimento repercute diretamente nos métodos de investigação. Duas grandes tradições, com diferentes objetivos, são claramente identificadas. Uma terá como questão os aspectos simbólicos e culturais que determinam as experiências particulares vivenciadas pelos sujeitos adoecidos. A outra vai ocupar-se de como tais sujeitos conjugam individualmente normas, valores, expectativas sociais, culturais e coletivas e desenvolvem formas especificas de pensar, explicar, sentir e agir nas situações que dizem respeito a seu adoecimento. Na primeira tradição o foco recai sobre os sistemas ordenados de ideias, símbolos e repre- 
sentações que significam o adoecimento e os processos de tratamento e cura, vividos individualmente. Na segunda, as experiências e práticas cotidianas dos sujeitos adoecidos são a questão. Fortemente marcada pela fenomenologia, a segunda tradição abrirá a possibilidade de conhecimento da experiência em primeira pessoa, ou seja, da dimensão singular da experiência subjetiva, fazendo do corpo fundamento da inserção do sujeito no mundo, ligando natureza e cultura e ressaltando a anterioridade da ação sobre a reflexão.

Tornar o corpo "premissa metodológica" dos estudos sobre a experiência - objetivo da antropologia de inspiração fenomenológica - é, nas palavras de Csordas ${ }^{26}$, tomá-lo como a base existencial da cultura e não como objeto a ser estudado em relação à cultura. Os estudos sobre experiência do adoecimento que fazem da corporeidade seu eixo paradigmático não estão especialmente interessados na função social que dada vivência de adoecimento teria para um sujeito ou grupo, nem tampouco nos estados mentais que podem acompanhar tais experiências particulares. Estes estudos se propõem, através do conhecimento das múltiplas possibilidades de experimentar um processo de adoecimento, conhecer como estas vivências constituem a cultura e o próprio sujeito. A análise de narrativas sobre experiências do adoecimento desloca-se da busca por categorias representacionais, sua classificação e diferenciação, para o conhecimento dos modos de produção desses processos de percepção e representação. A adoção da corporeidade enquanto paradigma libera a linguagem do domínio estrito da linguistica e semiótica e lhe atribui uma dimensão corporificada, rompendo dicotomias - mente/corpo, natureza/cultura - que por muito tempo organizaram estes estudos.

Essa mudança de referência coloca um desafio para a produção das narrativas de experiências de adoecimento. As narrativas que se organizam a partir de núcleos de sentidos e significações relacionados à etiologia, sintomatologia, patofisiologia, curso da enfermidade e tratamento, identificadas por Kleinman a partir das perguntas que observou acossar sujeitos adoecidos e por ele classificadas como baseadas em modelos explicativos, são aquelas que, pelo forte caráter reflexivo, estariam mais distantes do momento em que cultura e sujeito se objetificam como percepção e representação e revelariam pouco sobre seu modo de produção. Young ${ }^{24}$ e Groleau et al. ${ }^{27}$ identificaram dois outros modos de construção de narrativas de adoecimento: aquelas por protótipos, modeladas a partir de experiências de adoecimento anteriores, pessoais ou não, e as organizadas a partir de eventos significativos interconectados ao adoecimento por relação de contiguidade têmporo-experiencial. Menos reflexivas, se comparadas às narrativas baseadas nos modelos explicativos, estas duas modalidades, todavia, também não garantem acesso direto à experiência não refletida, nem revelam de modo genuíno e sem mediação a experiência que é anterior ao conhecimento e à nomeação dos estados mentais e da reflexão, por serem produto direto de interação contextualizada pesquisador-participante. Como então produzir relatos que revelem esta dimensão da experiência subjetiva relacionada ao adoecimento que é substrato das explicações e justificativas que se construirão sobre ela? Como produzir relatos capazes de revelar como tais experiências determinam a cultura e os sujeitos, ou seja, como produzir relatos que explicitem o modo de produção dos processos de percepção e representação?

\section{Experiência e Narrativa na Pesquisa em Saúde Mental de base fenomenológica e antropológica: estratégias metodológicas para a produção de relatos em primeira pessoa}

Davidson $^{28}$ indica, no contexto da pesquisa em saúde mental, como provocar este tipo de narrativa. Para ele, o desafio da produção das narrativas é tão relevante quanto o da sua análise. Atribui importância não vista antes às orientações e perguntas que devem dirigir o encontro entrevistador/entrevistado, caso a dimensão corporificada e situada de uma experiência vivida seja o que se busca. As regras gerais que apresenta em relação à produção das narrativas indicam que não convém convidar o participante a explicar as experiências ou as ações relatadas, perguntar-lhe por que faz tal ou qual coisa, ou mesmo convidá-lo a identificar fatores que influenciam suas experiências. Se assim o fizer, o entrevistador incitará a reflexão e a generalização, o que distanciará a narrativa da dimensão tácita da experiência. Muitas vezes tais cuidados aparecem sumarizados em máximas como: evite os por quês, utilize o advérbio "como", evite perguntas iniciadas com quê, quem, onde. Assim resumidos, tais cuidados são insuficientes. Perguntas do tipo "como é ter asma, ou diabetes, ou esquizofrenia?", ou "de que modo você interfere no curso da sua doença?" continuam sendo perguntas gerais e vagas que provocarão generalizações.

A centralidade da produção de narrativas em pesquisas empíricas sobre a experiência do ado- 
ecimento, e não apenas da sua análise, como sugere Davidson, é compreendida mais facilmente quando se examinam as noções de experiência e narrativa que embasam os estudos da antropologia médica centrados no método fenomenológico, as relações que estas duas noções estabelecem e as outras noções que delas decorrem.

Galin $^{29}$ sugere que a perspectiva da primeira pessoa defina não apenas o ponto de vista de quem vivencia um dado fenômeno, mas indique, sobretudo, um modo de descrevê-lo que articule consciência, subjetividade e agentividade. Este entendimento pode ser complementado pela definição de Varela e Shear ${ }^{30}$, que propõem que um evento descrito na primeira pessoa é uma experiência vivida associada a eventos mentais e cognitivos e que se expressam, nesta descrição, como relevantes e manifestos para um sujeito que pode relatá-los.

A definição sugerida por Varela e Shear ${ }^{30}$ introduz uma precisão fundamental do ponto de vista epistemológico e metodológico para a reflexão apresentada aqui. $\mathrm{O}$ acesso à experiência em primeira pessoa e o conhecimento que daí pode ser gerado é sempre mediado pela linguagem. A subjetividade que enuncia estes relatos é, portanto, acessível ao estudo empírico. Subjetivo não é idêntico a privado, ao contrário, é necessariamente aberto à validação intersubjetiva. Mesmo sob a forma de diálogo interior, onde o sujeito reconhece, nomeia e organiza os eventos de sua vida psíquica, a dimensão intersubjetiva está presente porque a experiência consciente só pode ser reconhecida ou comunicada na condição de um domínio prévio do uso da linguagem ${ }^{31}$.

A discussão acerca do acesso à experiência em primeira pessoa ou à singularidade da experiência subjetiva pode também ser bem ilustrada pela distinção, proposta por Zahavi ${ }^{32}$, entre o sujeito experiencial/fenomenológico e o narrativo/ hermenêutico, noções intimamente articuladas às de experiência e narrativa.

O sujeito experiencial/fenomenológico ${ }^{32}$ é um aspecto ou função do modo de doação da experiência a uma forma de corporificação imersa no mundo, estabelecendo uma centralidade de perspectiva. É um sujeito básico, pura experiência, sem reconhecimento ou reflexão, uma realidade experiencial imediata da consciência pré-reflexiva e tácita dos próprios estados mentais e corporais e do mundo circundante, que não é uma pré-condição transcendental da experiência nem construto narrativo reflexivo sobre ela. Trata-se de uma presença primária, uma autoafecção que simplesmente acontece, um sentimento básico do existir como um centro vital da experiência ${ }^{33,34}$.
Apresentado desta maneira o sujeito experiencial/fenomenológico fica fora da possibilidade de conhecimento pelas metodologias de investigação empírica, que sempre pressupõem linguagem e comunicação. A experiência e o sujeito da experiência de adoecimento e tratamento estudados com métodos da fenomenologia e da antropologia médica não se reportam a uma perspectiva da primeira pessoa em sentido estrito ${ }^{35}$. Não tratam de uma experiência pura porque já estão em interseção com a perspectiva da segunda pessoa $^{35}$, com a intersubjetividade e com a linguagem. Para comunicar a experiência subjetiva do processo de adoecimento, o sujeito precisa produzir uma narrativa mínima, que coloque em palavras este vivido. A despeito disso, este ainda será um relato de uma experiência absolutamente singular, não necessariamente articulada ao universo de significados socialmente compartilhados. A narrativa que decorre dessa articulação já é produto do sujeito narrativo.

O sujeito narrativo/hermenêutico ${ }^{32}$ é necessariamente reflectivo e intersubjetivo, depende do pertencimento do indivíduo a uma comunidade linguística, e expressa adesão a valores e significações ancoradas em uma tradição cultural. É construído na e através da narrativa, em um processo aberto, sujeito a revisões e mudanças de rumo, que acompanha a trajetória de vida do sujeito no tempo, oferecendo um relato que dê conta de suas origens, seu desenvolvimento e destino. O que somos, nesta perspectiva, depende da estória contada por nós e pelos outros. Como lembra Ricoeur $^{36}$, ao construir a narrativa de sua existência o sujeito produz o relato de uma vida do qual ele não é o autor quanto à existência e apenas é um dos coautores quanto ao sentido.

O sujeito narrativo/hermenêutico não é uma abstração. Trata-se de um sujeito narrativo corporificado ${ }^{37,38}$. Ele não se baseia exclusivamente nos recursos oferecidos pelo universo representacional. A ancoragem corporal contribui para a estrutura da experiência como perspectiva interna contínua no tempo. Experiências corporificadas possuem uma qualidade pré-narrativa que constitui uma "demanda por narrativa" 39 . A narrativa faz parte da vida antes de se exilar na escrita, sugere Ricour ${ }^{36}$.

O sujeito narrativo/hermenêutico pode transformar-se quanto a suas crenças e aparência física, mas se mantém ancorado em uma perspectiva subjetiva corporificada. Ele elabora uma concordância discordante ${ }^{36}$, sintetizando o heterogêneo através da mediação entre os eventos, a ação e o encadeamento da história narrada. 
O sujeito narrativo/hermenêutico ilumina o entendimento que Kleinman ${ }^{22}$ propôs para a experiência do adoecimento como resultante da dialética entre significação pessoal e categoria cultural, por um lado, e materialidade bruta dos processos biológicos, por outro. Articulam-se elementos que vão desde a experiência vivida corporalmente enraizada, passando pelo conjunto de recursos simbólicos disponíveis para lhe conferir algum sentido, chegando aos discursos especializados sobre o adoecimento que impactam o sujeito.

Good $^{40}$ afirma que as narrativas de experiência de adoecimento são uma dimensão intrínseca à experiência vivida e corporificada. Moldam, constituem e reconstroem a experiência de adoecimento, fornecendo diferentes contornos ao vivido subjetivo. Como visto acima, a experiência pura é inaccessível ao conhecimento do outro e, em alguma medida, do próprio sujeito que a vivencia. A narrativa se manifesta apenas a partir do momento em que a experiência atravessa a esfera da consciência pré-reflexiva para o campo da reflexão. $\mathrm{O}$ ato de contar a história (storytelling) de adoecimento e vida necessariamente cria alguma distância da experiência vivida corporificada e inaugura o processo de autoconhecimento. A narrativa, entretanto, pode sim revelar esse momento chave em que sujeito e objeto de conhecimento constituem-se mutuamente, num só tempo, explicitando o entrelaçamento entre corpo, sujeito, experiência, linguagem e cultura ${ }^{4,40}$. O desafio do investigador interessado nesta perspectiva da experiência é, então, buscar estratégias metodológicas que garantam a produção desta modalidade específica de relato.
Para acessar a dimensão da experiência, o entrevistador terá que incentivar o participante a retornar à sua própria experiência e espontaneamente descrever o que aconteceu, da maneira como se lembra de que isso aconteceu. Como fazer isso? Solicitando que relatem eventos marcados no tempo e no espaço, através de rememoração vívida, quase sensorial, de algo experienciado. O entrevistador guia o participante rumo ao encontro do contexto da situação vivenciada: o lugar, as circunstâncias, as sensações corporais que viabilizam a presentificação da situação específica. Em outras palavras, o entrevistador ajuda o sujeito da pesquisa a fazer emergir uma "fala encarnada", como formula Vermesch ${ }^{41}$, pesquisador francês que propôs a Entrevista de Explicitação, técnica de entrevista não estruturada que visa à verbalização introspectiva da dimensão procedural e implícita da ação.

Em relação à análise, a observação das referências e dos cuidados metodológicos gerais propostos na segunda seção é fundamental. Entretanto, autores mais especialmente interessados na dimensão vivida das narrativas - no campo da saúde mental - Davidson ${ }^{28,42}$, Corin e Lauzon ${ }^{43}$, dentre outros - têm proposto o envolvimento dos participantes na interpretação dos dados. Esta participação, todavia, não se restringe a um cuidado metodológico - legítimo, diga-se de passagem - com a validação dos dados e da análise. Os participantes não são aqui chamados a ocuparem uma posição reflexiva diante da análise e interpretação produzidas pelo pesquisador, mas a expressarem as experiências que têm diante da síntese analítica oferecida pelo pesquisador ${ }^{42}$.

\section{Colaboradores}

EM Leal e OD Serpa Junior trabalharam na concepção e na redação do artigo. 


\section{Referências}

1. Drummond JP, Silva E. Medicina Baseada em Evidências. Novo paradigma assistencial e pedagógico. São Paulo: Atheneu; 1998.

2. Greenhalgh T. Narrative based medicine in an evidence based world. BMJ 1999; 318:323-325.

3. Stuart M, organizador. Medicina Centrada na Pessoa: transformando o método clinico. Porto Alegre: Artmed; 2010.

4. Alves PC. A fenomenologia e as abordagens sistêmicas nos estudos sócio-antropológicos da doença: breve revisão crítica. Cad Saude Publica 2006; 22(8):1547-1554.

5. Kleinman A. Concepts and a model for the comparison of medical systems as cultural systems. $\mathrm{Soc} S \mathrm{Si}$ Med 1978; 12(2B):85-93.

6. Kleinman A, Eisenberg L, Good B. Culture, Illness, and Care Clinical Lessons from Anthropologic and Cross-Cultural Research. Ann Intern Med 1978; 88(2):251-258

7. Young A. Internalizing and externalizing medical belief systems: an Ethiopian example. Soc Sci Med 1976; 10(3-4):147-156.

8. Dartigues A. O que é a Fenomenologia. São Paulo: Editora Moraes; 1992.

9. Zahavi D. Husserl's phenomenology. Stanford: Stanford University Press; 2003.

10. Moreira DA. Metodo fenomenológico na pesquisa. São Paulo: Cengage Learning Editores; 2002.

11. Husserl E. A filosofia como ciência rigorosa. Coimbra: Revista Logos; 1952.

12. Giorgi A. Sketch of a psychological phenomenological method. In: Giorgi A, organizador. Phenomenological and psychological research. Pittsburgh: Duquesne University Press; 1985. p. 8-22

13. Merleau-Ponty M. Fenomenologia da Percepção. São Paulo: Martins Fontes; 1999.

14. Levasseur JJ. The problem of bracketing in phenomenology. Qualitative Health Research 2003; 13(3):408-420.

15. Davidson L. Phenomenological research in schizophrenia: from philosophical anthropology to empirical science. Journal of Phenomenological Psychology 1994; 25(1):104-130.

16. Gallagher S, Zahavi D. The Phenomenological Mind. An introduction to philosophy of mind and cognitive science. London: Routledge; 2008.

17. Giorgi A. The descriptive phenomenological method in psychology. A modified Husserlian approach. Pittsburgh: Duquesne University Press; 2009.

18. Moustakas C. Phenomenological research methods. Thousand Oaks: Sage Publications; 1994

19. Smith JA, Flowers P, Karkin M. Interpretative Phenomenological Analysis. Theory, Method and Research. Thousand Oaks: Sage Publications; 2009.

20. Van Manen M. Researching lived Experiences. Human science for action sensitive pedagogy. Albany: SUNY Press; 1990

21. Giorgi A. Description versus Interpretation: competing alternative strategies for qualitative research. Journal of Phenomenological Psychology 1992; 23(2):119-135.
22. Kleinman A. The Illness Narratives: suffering, healing and the human condition. New York: Basic Books Inc; 1988.

23. Young A. When rational men fall sick: an inquiry into some assumptions made by medical anthropologists. Cult Med Psychiatry 1981; 5(4):317-335.

24. Young A. The Anthropologies of Illness and Sickness. Annual Review of Anthropology 1982; 11: 257 285.

25. Kleinman A, Benson P. Anthropology in the Clinic: The Problem of Cultural Competency and How to Fix It. PLoS Medicine 2006; 3(10):e294.

26. Csordas TJ. Corpo. Significado. Cura. Porto Alegre: Editora UFRGS; 2008.

27. Groleau D, Young A, Kirmayer LJ. The McGill Illness Narrative Interview (MINI): An Interview Schedule to Elicit Meanings and Modes of Reasoning Related to Illness Experience. Transcultural Psychiatry 2006; 43(4):697-717.

28. Davidson L. Living Outside Mental Illness. Qualitative studies of recovery in Schizophrenia. New York: New York University Press; 2003.

29. Galin D. Separating First-personness From the Other Problems of Consciousness, or "You had to have been there". In: Varela FJ, Shear J, editors. The View from Within. First-person approaches to the study of consciousness. Thorverton: Imprint Academic; 1999. p. 222-229.

30. Varela FJ, Shear J. First Person Account : why, what and how. In: Varela FJ, Shear J, editors. The View from Within. First-person approaches to the study of consciousness. Thorverton: Imprint Academic 1999. p. 1-14.

31. Sellars W. Empirisme et Philosophie de l'Esprit, Combas: Éditions de l'Éclat; 1992.

32. Zahavi D. Subjectivity and Selfhood. Investigating the first-person perspective. Cambridge: MIT Press; 2005.

33. Sass LA. Self-disturbance in schizophrenia: hyperreflexivity and diminished self-affection. In: Kircher T, David AS, editors. The Self in Neuroscience and Psychiatry. Cambridge: Cambridge University Press; 2003. p. 242-271.

34. Sass LA, Parnas J. Schizophrenia, Consciousness and the Self. Schizophrenia Bulletin 2003; 29(3):427444

35. Northoff G, Heinzel A. The self in philosophy, neuroscience and psychiatry: an epistemic approach. In: Kircher T, David AS, editors. The Self in Neuroscience and Psychiatry. Cambridge: Cambridge University Press; 2003. p. 40-55.

36. Ricoeur P. Soi-même comme un autre. Paris: Seuil 1990.

37. Menary R. Embodied Narratives. Journal of consciousness studies 2008; 15(6):63-84.

38. Thornton T. Psychopathology and Two Kinds of Narrative Account of the Self. Philosophy, Psychiatry and Psychology 2003; 10(4):361-367.

39. Kerby P. Narrative and the Self. Indiana: Indiana University Press; 1993. 
40. Good B. Medicine, rationality, and experience. Cambridge: Cambridge University Pres; 1994.

41. Vermersch P. L'entretien d'explicitation. $4^{\text {en }}$ Edition. Issy-les-Molineaux: ESF; 2003.

42. Davidson L. Phenomenological and Participatory Research on Schizophrenia: Recovering the Person in Theory and Practice. Journal of Social Issues 1997; 53(4):767-784.

43. Corin E, Lauzon G. Positive withdrawal and the quest for meaning: the reconstruction of experience among schizophrenics. Psychiatry 1992; 55(3):266278.

Artigo apresentado em 17/03/2013

Aprovado em 30/05/2013

Versão final apresentada em 27/06/2013 